\title{
All Generalisations Are Dangerous, Including This One: Pigeon-Holing On-Line Purchases
}

Alun Epps, University of Wollongong in Dubai, United Arab Emirates

\begin{abstract}
Building upon the review of contemporary literature, this paper reports on studies in the field of the of web-based shopper market segmentation. It finds that unique groups of consumers perceive the internet differently; and that the key to successful web-based marketing strategy is clear segmentation and division. Using the findings of an empirical study comprising a set of focus groups and an electronic survey, criteria for segmenting web-based shoppers by; gender, age, education, life stage, ethnic type and previous internet usage are offered and described. These criteria will be of interest to marketing academics and professionals alike.
\end{abstract}

Keywords: Academic Department: marketing, web-based shopping, segmentation

\section{INTRODUCTION}

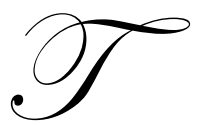

his paper suggests new criteria for segmenting internet users who shop and buy on line. These classifications emerge from an empirical study whose specific objectives included determining to what extent consumer segmentation variables, specifically; gender, ethnic group, age, educational level, current web-based shopping media usage and family life stage effect the perception of web based shopping.

The results of the study suggest that the advantages and disadvantages of web-based shopping can be broken down into practical as well as psychological and that groups of consumers when divided, by either; age, gender, ethnicity, education level or previous web-based shopping experience; perceive the advantages and disadvantages differently. Another objective of the study was to define and classify the parameters of the practical and psychological advantages as well as disadvantages of web-based shopping media and thus; the divisions used in the study were; practical advantages, practical disadvantages, psychological advantages and psychological disadvantages (Epps 2006). The study suggests that these differences can be used by web-capitalists, to predict how discrete groups of customers will behave, and to act as a guide in tailoring their offer accordingly. The results of this study that surveyed potential or actual web-based shoppers showed the following results after an e-mail administered questionnaire.

This paper then, takes the results on to look at new uni-variate as well as composite ways of segmenting the consumer market for web-based shoppers and to see what value these criteria can be to marketers and webcapitalists.

Table 1: Significance Test Results for Empirical Study

\begin{tabular}{|c|c|c|c|c|}
\hline & Practical Advantages & $\begin{array}{c}\text { Psychological } \\
\text { Advantages }\end{array}$ & $\begin{array}{c}\text { Practical } \\
\text { Disadvantages }\end{array}$ & $\begin{array}{c}\text { Psychological } \\
\text { Advantages }\end{array}$ \\
\hline Gender & .014 & & & \\
\hline Ethnicity & .019 & .028 & .047 & \\
\hline Age & & & .017 & \\
\hline TEA & & .035 & .000 & \\
\hline Usage & .000 & & & .000 \\
\hline Family & & & & \\
\hline
\end{tabular}




\section{LITERATURE REVIEW}

The academic study of web-based shopping behaviour (Hoffman and Novak; 1996, Kristula, 2001; Bhatnagar and Ghose, 2004) is as old as the activity itself; and much of the established and accepted theories of consumer behaviour and how they relate contemporary research in the field of shopping web-based environments (Hoffman and Novak, 1996; Shih, 1998; Porter, 2001; Ranchhod and Gurãu, 2004); still holds true today. The five stages (problem recognition, search, evaluation decision and post-purchase); of consumer buyer behaviour (Engel Kollat and Blackwell, 1978); suggests a framework for web-based shopping and previous studies (Epps, 2004; Epps, 2006) started to examine the positive and negative influences on shopping within web-based environments. The act of segmentation or ways in which common groups of consumers behave whilst in web-based environments (Pollay and Mittal, 1993; Dholakia and Uusitalo, 2002; Teo, 2001; Kolsaker and Payne, 2002; Kimber, 2002; Epps, 2004); and thus exhibit behavioural differences in following the five stage model are the key focus of this paper. The sequential model of consumer buying behaviour, although developed before the use of web-based shopping was available, still forms a useful framework for a sequence of web-based purchasing. To varying degrees, the entire process through can be aided by the advent of web-based shopping media.

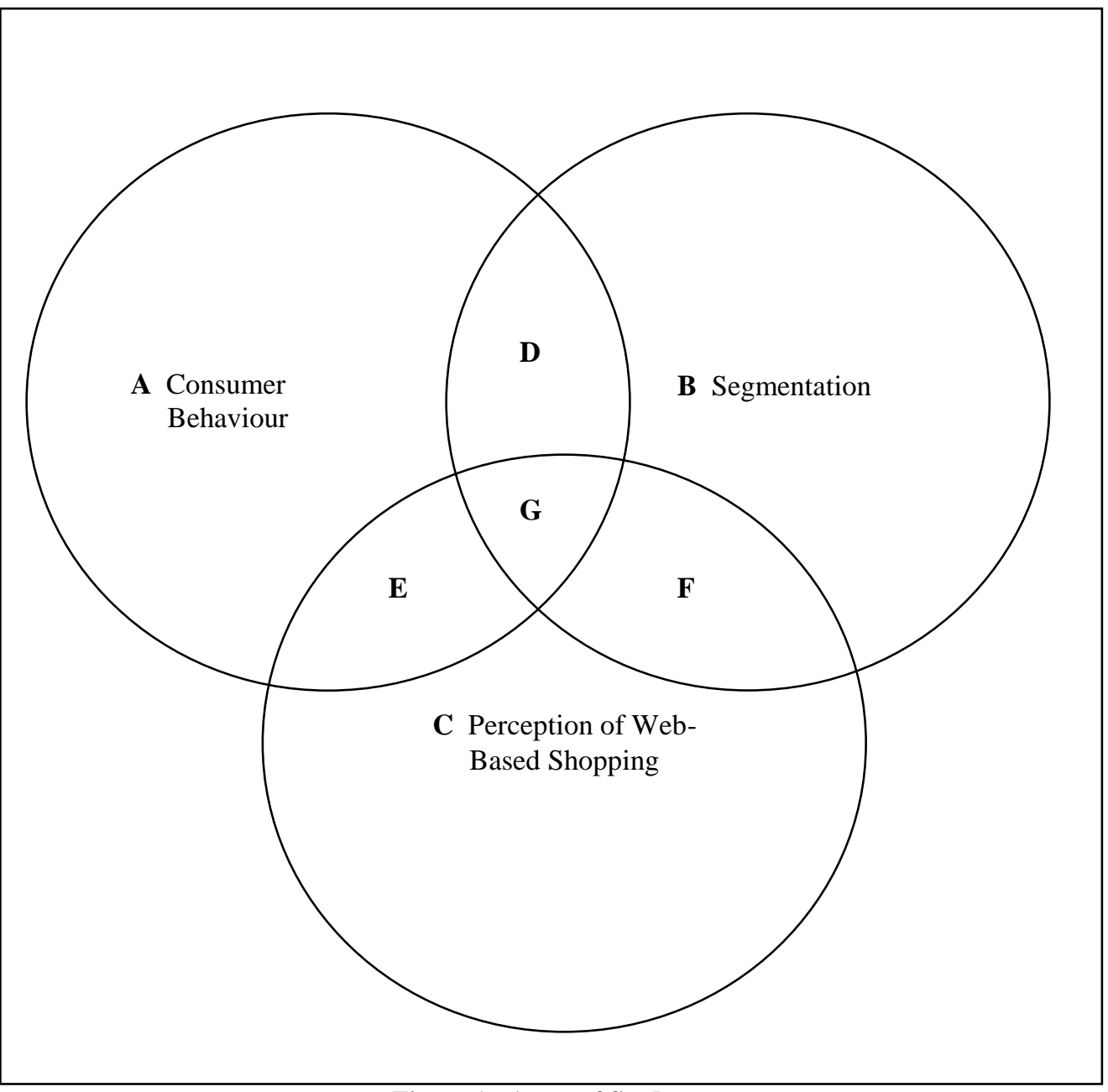

Figure 1: Areas of Study 
Numerous variables (Evans et al, 2001; Coyle and Thorson, 2001; Gould and Lerman, 1998) that can influence the usage of web-based shopping and there are positive and negative influences on web-based shopping as well as a distinction between the advantages (Davis, 1993; Moon and Kim, 2001) and disadvantages (Liebermann and Stashevsky, 2002; So and Sculli, 2002;) of this mode of shopping. The rationale as to why consumers choose to shop in web-based environments could be broken down into two areas; the practical or utilitarian benefits and the hedonic or pleasure-seeking areas. Conversely, this study suggests that there are many factors that discourage webbased shopping; and these could arguably be broken down into the areas of pragmatic and the pleasurable.

Thus, much of the research in this field is related to at least one of three areas of research; consumer behaviour (Engel Kollat and Blackwell, 1978; Butler and Peppard, 1998; Maklan et al, 2002; segmentation (Bhatnagar and Ghose, 2004; Kotler, 1997; Kimber, 2002) as well as the perception of web-based shopping (Chandon et al, 2000; Babin, Darden, and Griffin, 1994; Balabanis and Reynolds, 2001; Maklan, 1999; Ryan and Valverde, 2005; Park and Kim, 2003). This study links the three fields as can be seen in Figure 1. In this figure; that is a Venn diagram stating the academic areas covered by this study; there are three main sectors; A, B and C that all intersect with one other; as well as all three intersecting with each other.

In sector A and central to this study is the notion of consumer behaviour; (Engel Kollat and Blackwell, 1978; Engel, Blackwell and Minniard, 1986; Sheth and Howard, 1974; Azjen and Fishbein, 1980), and what drives different groups of "like" consumers to behave in certain ways; (Lee and Overby; 2004; Assael, 1998; Balabanis and Reynolds, 2001; Harvin, 2000; Menno and Kahn, 2002). The concept has received much coverage since 1996 (Butler and Peppard, 1998; Maklan et al, 2002; Hoffman and Novak, 1996; Shih, 1998; Citron et al, 2000); and continues to do $\mathrm{o}$ as the science evolves.

In sector $\mathrm{B}$, consumer behaviour is closely allied to the notion of market segmentation because to effectively target e-shoppers, it is vital for companies to try and understand the nature of heterogeneity (Bhatnagar and Ghose, 2004; Cho and Park, 2001; Kotler, 1997). Academics and marketers segment markets to identify the most profitable groups and a similar approach has been considered relevant for internet marketing (Burke, 1997; Bonn et al, 1999; Lawrence et al, 2000). The aim of this process is to utilise organisational resources to serve the customer better and as Peterson et al. (1997) state, an important unanswered question relates to how retailers can segment online shoppers. The past present and future of web-based shopping is in a state of flux (Epps, Govers and Go, 2007); and the wise marketer must be abreast of new developments that determine new segments based on demographic as well as behavioural criteria.

Sector C suggests that, consumers typically view shopping as an essential task to acquire goods and for the utilitarian purchaser, shopping is not automatically pleasurable whilst for many shopping is an enjoyable event. For those who do not like online shopping, much of the literature in the field discusses the pertinence of the social aspects of "real" shopping (Hamilton and Hewer, 2000; Quelch and Klein, 1996; Coyle and Thorson, 2001; Francis and White, 2004) versus the anti-social aspects of "virtual" shopping (Burton, 2002; Prabhaker, 2000; Retter, 2002). Intersection D represents the linkages between consumer behaviour and segmentation. The literature clearly demonstrates this from an early stage, in that different or discrete groups of consumers (segmentation) act in different ways (behaviour) when shopping and especially when shopping in web-based environments; (Ventkatesh, 1998; Brown, Pope and Voges, 2003; Kimber, 2002; Hamilton, 2000).

Intersection $\mathrm{E}$ suggests the relationship between consumer behaviour and the perceptions of web-based shopping. The literature, (Lee and Overby, 2004, Assael, 1998; Menon and Kahn, 2002) suggest that there is a link between what people think and how they behave. The original research and findings of this study go some way in supporting this and the implications of this will be discussed in this section. It could be that there are mainly two extremes of shopper; those that have never shop on-line and never will and those that have shopped on line and after having done this would consider it perfectly normal to continue doing so in future situations.

Intersection F implies the linkage between segmentation and the perceptions of web-based shopping. This notion is built on the theoretical foundation suggested in chapters three and four (Balabanis and Reynolds, 2001; Yang and Jun, 2002; Hamilton and Hewer, 2000; Earl and Khan, 2001). This study upon which this paper is based 
suggests a way of measuring the perceptions or attitudes of individuals towards the medium and based upon this, how the consumers behave because of these pre-conceptions. The basic tenet of this interface is that discrete groups of people perceive the concept of web-based shopping differently. The key differences brought out in this study were ethnicity and previous shopping behaviour experience where three areas of significance were demonstrated in each case.

Intersection $\mathrm{G}$ can be viewed as the net contribution of this paper as it is the sum or product of the concepts of; consumer behaviour, segmentation and the perceptions of web-based shopping (Epps, 2006). The argument here is that distinct groups of individual shoppers or non shoppers (segmentation) appreciate the advantages and disadvantages of the shopping medium (perception) in different manners and therefore act or at least intend to act in ways which may be predictable and therefore be turned to the advantage of to the web-capitalist and academic alike. One concept that could be explored in future studies is, which of the three areas has the greater influence on the others; in that each circle (A, B or C) become factors in an equation and each subsection (D, E or F) becomes the sum or even product of the equation, so that $\mathrm{A}+\mathrm{B}(\mathrm{D})=\mathrm{C}$ or A influences $\mathrm{B}(\mathrm{D})$ and this leads to $\mathrm{C}$. Each of the six variants on this theme is discussed below.

It could be, that in the case of intersection $\mathrm{D}$; consumer behaviour (A) determines how the particular segment (B) will behave and that will then effect that segment's perception of web-based shopping behaviour (C); or that a segment (B) behaves (A) in a certain way and has certain perceptions of web-based shopping (C).

In intersection $\mathrm{E}$, a pattern of behaviour (A) determine perceptions of web-based shopping $(\mathrm{C})$ and this will form the basis of the behavioural segment (B); or it could be that the perception of web-based shopping (C) influences behaviour (A) so that this will then become a behavioural segment (B).

Likewise, in the case of intersection F, a segment (B) could have certain perceptions (C) that would influence their ultimate behaviour (A); or, finally the perception of web-based shopping (C) could determine the segment (B) that would behave (A) in a predictable way.

The answer to all six of these questions would be that; it is difficult to determine what the dominant aspect of web-based shopping is; but that all three areas of contribution are indeed intertwined as suggested by the Venn diagram shown in Figure 1 above. This study then begs the questions; how strong the linkages between the segmentation variables used for web-based shoppers and, how the consumers behave; and what their perceptions of the advantages and disadvantages of web-based shopping are. The remainder of this paper sets out to go some way to address these issues and to suggest how through further study, these could be answered more comprehensively.

\section{DISCUSSION}

The general suggestion of this paper is that groups of consumers when segmented by standard academic criteria (Kotler, 1997; Teo, 2001); as well as industry standards such as ACORN, AGB, MOSIAC; and adaptive taxonomies; (Venkatesh, 1998; Kimber, 2002; Kaufman-Scarborough and Linquist, 2002); behave differently when shopping in web-based environments. Data generated from the group discussions was qualitative in nature and highlighted areas for further investigation in the main study. It was suggested that different types of internet user groups, segmented by the standard criteria including age, life stage, ethnicity, education, internet shopping usage and gender perceive each of the four sectors of web-based shopping differently. The main quantitative study set out to test this theory and based on a series of notions whereby each of the segmentation criteria and all four of the question sectors were cross-referenced and tested using descriptive and significance tests.

This then suggests that segmentation criteria do play a significant role in web-based shopping; and suggests how groups will behave within a margin of predictability. It is suggested that within a certain degree of confidence $(0.05)$ that; if for example females, behave in a certain way in the survey sample; i.e. preferring the psychological advantages of web-based shopping to the practical; that the female web-based shopping population as a whole would behave in this way. With further testing and calibration, these details can be more reliably confirmed. 
The potential advantages of segmenting by using a typology determination and measurement instrument as suggested by this thesis, is clearly apparent from this study as in the literature, group discussions as well as pilot and main studies. Further suggestions as to how more detailed segmentation could take place, for example composite segmentation such as "European", "males" that are in the "26-35" age bracket, or indeed any combination of the classification options within each of the six variables will be discussed in the conclusions and implications for further research section of this paper. This type of multi-variate or composite psychographic segmentation; (Kimber, 2002; Venkatesh, 1998; Kaufman-Scarborough and Lindquist, 2002); using various combinations of segmentation criteria could provide real benefits to the academic and business communities alike.

In a similar taxonomy determination chart to the one suggested by; Kimber et al (2002) (e-types), Kaufman-Scarborough and Linquist, (2002), Hamilton, 2000, (shopper typologies); this paper has suggested 6 segmentation bases for gender, ethnicity, age, education, previous internet shopping and family stage, that can be seen in Table 2 below.

Table 2: New Taxonomy Bases

\begin{tabular}{|c|c|c|c|c|c|}
\hline Taxonomy & Type One & Type Two & Type Three & Type Four & Type Five \\
\hline Gender & Male & Female & & & \\
\hline Ethnicity & European & Indian & Arabic & African $*$ & SE Asian $*$ \\
\hline Age & $16-25$ & $26-35$ & $36-45$ & $46-55$ & $56+$ \\
\hline Education & 16 & 18 & Bachelor & Master & PhD \\
\hline Previous & Never & Not again & May do & Will again & Regular \\
\hline Family & With parents & Single & Wed no child & Wed \& child & Empty nest \\
\hline Income* & $<\$ 10,000 *$ & $\$ 11,000-\$ 50,000 *$ & $\$ 51,000-$ & $\$ 101,000-$ & $>200,000 *$ \\
& & & $\$ 100,000 *$ & $\$ 200,000 *$ & \\
\hline
\end{tabular}

* not used in author's empirical study

Each of the six taxonomy bases and their contribution will be examined in turn

\subsection{Taxonomy For Gender}

This taxonomy could only be split into two as there are generally only two gender types. There was only one questionnaire area that demonstrated a significant difference in the gender taxonomy and that was the practical advantages, although there were differences in the perception of web-based shopping. Gender is an established way to segment markets (Kotler, 1997; Sen et al, 1998); and this study would suggest that it is still valid practice in webbased environments. The simplicity of this taxonomy (male or female does not merit a table and description).

\subsection{Taxonomy For Ethnicity}

Along similar lines and based on the same proforma, a taxonomy for ethnicity or at least ethnic origin could be devised as shown in Table 3 below. In further studies, a wider range of types could be included, such as African or South East Asian, as are included in the table. This study only used three types for the ethnicity segmentation; and this was because there were only three obvious large groups in the sample. If the study had included substantial numbers of South East Asians, Hispanics, Africans or other clear-cut ethnic groups, then these too would have appeared in the options. The results for this taxonomy were very significant in that three areas; practical advantages, psychological advantages and practical advantages did display a reading of 0.05 in the ANOVA tests. Ethnicity and cultural classification (Korgaonkar, 2001; Pollay and Mittal, 1993; Wang, 1999; Hofstede, 1980) is often a personal segmentation criterion to ask a respondent to classify themselves as; and it sometimes equally hard to determine. In this study, ethnicity was determined from the nationality given by the respondent in the questionnaire. There are of course chances that the nationality would not reflect the ethnicity of the respondent. For the purposes of completeness then, this paper includes African and South East Asian. Whilst these additions in no way attempt to present a complete picture of ethnicity, they do cover more types than in the original study. It was interesting to note 
that there were apparently no Africans or South East Asians responding to the original survey, or at least not an amount signifying enough to merit its own criterion.

Table 3: Ethnicity Taxonomy

\begin{tabular}{|c|c|l|}
\hline Type & Description & \multicolumn{1}{c|}{ Characteristics } \\
\hline 1 & European & $\begin{array}{l}\text { Originally from Europe, mainly living in Europe or the Americas, South Africa, Australia, } \\
\text { New Zealand }\end{array}$ \\
\hline 2 & Indian & Originally from India, Pakistan, Sri Lanka, Nepal or Bangladesh \\
\hline 3 & Arabic & Arabic speaking, predominantly Muslin religion \\
\hline 4 & African & Originally from Sub-Saharan Africa \\
\hline 5 & South East Asian & Originally from South East Asia \\
\hline
\end{tabular}

\subsection{Taxonomy For Age}

Age was segmented into five convenient areas $(16-25,26-35,36-45,46-55,56+)$ on a logical or ordinal basis to give clear 10 year gap groups or sub-generations. It could have been done with teens, 20s, 30s and so on but this method was seen as being most convenient and practical at the time. Although only one area, practical disadvantages shown significance in the ANOVA tests, there were some differences. Age, is an important factor in determining shopping behaviour both on and off line (Kotler and Armstrong, 2004; Troccia and Janda, 2000; Liebermann and Starshevsky, 2002); and this study would suggest that there are criteria that show higher levels of agreement in more areas; (previous usage and ethnicity). Following a similar pattern, the taxonomy of age could be devised based on the division shown below in Table 4, or more conventional socio-demographic standards.

Table 4: Age Taxonomy

\begin{tabular}{|c|c|l|}
\hline Type & Description & \multicolumn{1}{c|}{ Characteristics } \\
\hline 1 & $16-25$ & Living with parents, single, low income, in full time-education \\
\hline 2 & $26-35$ & Web-savvy, university graduates, no children or young children own income \\
\hline 3 & $36-45$ & Peak earning potential, young children \\
\hline 4 & $46-55$ & High earning, grown up children \\
\hline 5 & $56+$ & Empty nest, considering retirement \\
\hline
\end{tabular}

\subsection{Taxonomy For Education}

The up-scale; i.e. affluent, educated, ambitious, web-savvy; nature of web-based shoppers (Menno and Kahn, 2002; Troccia and Janda, 2000; Dholakia, 2002; Lawrence et al, 2000) suggests that education would be a factor as it would assume sufficient wealth to have access to the internet, funds to make purchases and computer dexterity to operate the system. The only area where significance of less that 0.05 was shown in education was in the psychological advantages. The terminal education age achieved by the respondents could be developed and generalised as shown below in Table 5, or again adjusted along more conventional lines.

Table 5: Terminal Education Age (TEA) Taxonomy

\begin{tabular}{|c|c|l|}
\hline Type & Description & \multicolumn{1}{c|}{ Characteristics } \\
\hline 1 & 16 & No education past compulsory school leaving age of 16 \\
\hline 2 & 18 & No education past the age of 18 \\
\hline 3 & Bachelors & Has successfully completed a bachelors level degree, s must be aged 21 or above \\
\hline 4 & Masters & $\begin{array}{l}\text { Has successfully completed master's degree and bachelor's degree. Will probably be aged 25 } \\
\text { or above }\end{array}$ \\
\hline 5 & $\mathrm{PhD}$ & $\begin{array}{l}\text { Has successfully completed doctorate, bachelors and masters degrees. Will be aged 25 years or } \\
\text { above }\end{array}$ \\
\hline
\end{tabular}




\subsection{Taxonomy For Previous Internet Shopping}

This taxonomy area, like ethnicity had three sectors that showed significant agreement of less that 0.05 in the ANOVA tests, Practical Advantages, Practical Disadvantages and Psychological Disadvantages. It can be seen that previous behaviour goes a long way in determining future behaviour in web-based shopping (Rangswarmy and Gupta, 1999; Goldsmith and Flynn, 2005; Sexton et al, 2002); and is still seen as an important criteria (Kimelfeld and Watt, 2001; Salisbury et al, 2001; Assael, 1998) when measuring attitude towards the media. This criterian became a control group to see if the instrument worked and as such, this would seem to be the case. The adoption/non adoption of the web-based shopping medium could be similar to driving automatic transmission as opposed to manual automobiles in that those that drive manual cars would never drive an automatic and those that drive an automatic car would never go back to driving a manual one.

Table 6: Previous Internet Shopping Experience Taxonomy

\begin{tabular}{|c|c|l|}
\hline Type & Description & \multicolumn{1}{c|}{ Characteristics } \\
\hline 1 & Never & $\begin{array}{l}\text { Reluctant to purchase, wary of giving out details on-line, not confident with computers or the } \\
\text { internet, may not like using credit cards and/or access to the internet }\end{array}$ \\
\hline 2 & Not again & $\begin{array}{l}\text { Have bought on-line before and has experienced poor customer service, slow delivery, delivery } \\
\text { of wrong item, accidental or criminal misuse of funds }\end{array}$ \\
\hline 3 & May do & $\begin{array}{l}\text { Curious to use the medium, can appreciate the advantages but happy to spend leisure time } \\
\text { going to a "real" shopping environment }\end{array}$ \\
\hline 4 & Will again & $\begin{array}{l}\text { Occasional purchasing on-line mostly books and tickets. Tend to check out prices on-line and } \\
\text { then actually buy from bricks and mortar shops. }\end{array}$ \\
\hline 5 & Regular & $\begin{array}{l}\text { Full confidence in the system, make purchases of high involvement items on-line, all utilities } \\
\text { and high amount of gifts paid for on-line. }\end{array}$ \\
\hline
\end{tabular}

\subsection{Taxonomy For Family Stage}

There were no areas where a significance of less than 0.05 was demonstrated. It can be concluded that the stage in ones family or life cycle is not a significant factor in determining their perception of the value of web-based shopping. However, for the purposes of completeness, the table is presented below in Table 7.

Table 7: Family Life Stage Taxonomy

\begin{tabular}{|c|c|l|}
\hline Type & Description & \multicolumn{1}{|c|}{ Characteristics } \\
\hline 1 & With parents & Not married and living with parents \\
\hline 2 & Single & Not married and not living with parents \\
\hline 3 & Wed no child & Married with no children \\
\hline 4 & Wed \& child & Married with children living at home \\
\hline 5 & Empty nest & Married with all children having left home \\
\hline
\end{tabular}

\subsection{Taxonomy For Annual Income}

A further criterion of salary or disposable income (Lawrence et al, 2000; O'Conner and Galvin, 2001; Tse, 1996) could be introduced. In the empirical study, annual or monthly salary was not used as a segmentation base as it was seen as being too intrusive and personal as many of the original respondents in the snowball sample were known to the author who did not wish to deter, delay or incur the falsification or incompleteness of the questionnaires. However a rough indicator of what could be used based on annually earnings in Dubai where there is a large gulf between top and bottom is shown in a five option table below. 
Table 8: Annual Incomes in US Dollars Taxonomy

\begin{tabular}{|c|c|l|}
\hline Type & Description & \multicolumn{1}{c|}{ Characteristics } \\
\hline 1 & $<\$ 10,000$ & Earning an annual salary of less than $\$ 10,000$ US \\
\hline 2 & $\$ 11,000-\$ 50,000$ & Earning an annual salary of between $\$ 11,000$ and $\$ 50,000$ US \\
\hline 3 & $\$ 51,000-\$ 100,000$ & Earning an annual salary of between $\$ 51,000$ and $\$ 100,000$ US \\
\hline 4 & $\$ 101,000-\$ 200,000$ & Earning an annual salary of between $\$ 100,000$ and $\$ 200,000$ US \\
\hline 5 & $>200,000$ & Earning an annual salary of more than $\$ 200,000$ US \\
\hline
\end{tabular}

\section{CONCLUSIONS}

From the main perspective of the study, shopping using the internet does have its advantages and disadvantages and these are viewed differently for distinct groups of people in that groups of consumers when divided either by; age, gender, ethnicity, education level or previous web-based shopping experience perceive the advantages and disadvantages differently. These differences as highlighted by the taxonomy or segmentation system used herein can be used by academics and managers alike to predict how discrete groups of customers will behave and as a guide for them to tailor their web-based offer accordingly.

The two segmentation criteria out of the six used in the empirical study, where the most significance was shown were those of ethnicity and previous web-based shopping experience. Therefore what can be ultimately concluded is that for a group of potential internet shoppers; especially in a "random" sample in a study such as this and arguably in a larger, difficult to determine population, i.e. all potential internet shoppers; is that where a consumer comes from, i.e. ethnic background (European, Indian or Arabian) and their level of previous involvement in internet shopping; are both important factors in determining how an individual or group from an ethnic or previous usage segment will perceive web based shopping; and therefore potentially behave when presented with the opportunity to purchase on line.

For a manager to know, if only to a certain extent how their customers or existing customers will behave is an invaluable advantage. Gurãu and Ranchhod (2002) state that it is essential to have measurement and monitoring systems in order to develop profitable new customer propositions for different customer segments. This requires the design of appropriate measures, including the return on investment, and systems necessary to deliver timely and accurate information. This study shows if only in a limited way, the behavioural differences in types such as gender, age, life stage, usage, education and ethnicity and how they can be manifested in web-based shopping behaviour (Burton, 2002; Dholakia, 1999; Menon and Kahn, 2002). Knowing how these types or composites of consumers will behave is a valuable asset to the marketing professional.

A prediction of how types of consumers will behave is essential to marketing managers who are offering web services (Bhatnagar and Ghose, 2004); and a model such as developed in this study, can be argued to have important implications for organisations who wish to pigeon-hole their market or customer base into rigid types. In a similar manner to the Myers Briggs; (Briggs Myers and Briggs 2004) and Belbin (Belbin 2004); typology determination tests, the series of questions can place any individual consumer or groups of consumers into clear behavioural types, either as a discrete type or combination of two or more of the sectors contained therein.

Finally, the next obvious stage would be to investigate a composite rather than single variable model that would classify each of the six (or more) bases for web-based consumer segmentation in a multi-variate system. If the five bases (age, education, life stage, nationality and previous experience) each with five options were used, there would be 3,125 combinations (five bases multiplied by five options per base) possible combinations or segments and 6,250 combinations when gender is used (times two, male and female) and 31,250 combinations, if the income base was used (five more options). This composite and multi-faceted model could describe by self-referencing, an individual's type, but also to an extent their behavioural patterns, could be calculated and predicted. This would be a move towards an individual's and a like group of indviduals' predictive shopping behaviour.

Dr. Alun Epps is an Assistant Professor of Marketing in the College of Undergraduate Studies at the University of Wollongong in Dubai. He holds a PhD from the University of Wales, an MBA from the University of 
Portsmouth and a BA from London South Bank University. He is a Chartered Marketer as well as a Member of the Chartered Institute of Marketing. Dr. Epps's current research includes; consumer behaviour in computer mediated environments, search engine marketing, and the use of information and communication technologies in small to medium enterprise marketing.

\section{REFERENCES}

1. $\quad$ Ajzen, I. 1980. Attitudes Personality and Behaviour, Chicago IL: Dorsey Press.

2. $\quad$ Ansoff, I, 1957, Strategies for diversification, Harvard Business Review, September/October 1957

3. Assael, H. 1998 Consumer Behaviour and Marketing Action, $6^{\text {th }}$ Ed. USA, South Western Publishing.

4. Babin, B., Darden, W. and Griffin, M. 1994, Work and/or Fun: Measuring Hedonic and Utilitarian Shopping Value, Journal of Consumer Research, vol. 20 (March), pp. 644-656.

5. Balabanis, G. and Reynolds, N. 2002, Consumer attitudes towards multi-channel retailers' Web sites: The role of involvement, brand attitude, Internet knowledge and visit duration Journal of Business Strategies; Huntsville; Fall.

6. BCG, 2005, online, available, http://www.wiley.co.uk/innovate/website/pages/atoz/bcg-01.ht

7. Belbin, 2004, Belbin's Team Role theory in action online, online available http://www.belbin.com/videobtpt.html

8. Bhatnagar, A, Ghose, S, 2002, Segmenting consumers based on the benefits and risks of Internet shopping, Journal of Business Research, vol. 57, 1352-1360.

9. Bhatnagar, A, Ghose, S, 2004, A latent class segmentation analysis of e-shoppers, Journal of Business Research, vol. 57, pp. 758-767.

10. Bonn, M. et al. 1999. Predicting a behavioural profile for pleasure travellers on the basis of internet use segmentation, Journal of Travel Research, vol. 37, no. 4, pp. 333-341.

11. Briggs Myers, I and K Briggs, 2004, Introducing Psychological Type online http://www.myersbriggs.org/ethical/guidelines.cfm

12. Brown, M, Pope, N and Voges, K Buying or browsing? 2003, An exploration of shopping orientations and online purchase intention, European Journal of Marketing, vol. 37, Issue 11/12, pp 1666-1684

13. Burke, R, 1999, Do you see what I see? the Journal of the Academy of Marketing Science, vol. 25 (4) pp. 352-360.

14. Burton, D. 2002. Postmodernism, social relations and remote shopping. European Journal of Marketing vol. 36, no. 7/8, pp 792-810.

15. Butler, P. and Peppard, J. 1998. Consumer purchasing on the Internet: processes and prospects, European Management Journal, vol. 16, no. 5, pp 600-610.

16. Cho, N. and Park, S. 2001. Development of electronic user-consumer-satisfaction index (ECUSI) for Internet shopping, Industrial Management and Data Systems, vol. 101, no 8, pp 400-406.

17. Citrin, A. et al. 2000. Adoption of Internet shopping: the role of consumer innovativeness, Industrial Management and Data Systems, vol, 100 no.7, pp 294-300.

18. Coyle, J., Thorsen, E., 2001. The effects of progressive levels of interactivity and vividness in web marketing sites, Journal of Advertising vol. XXX) fall, pp. 65-77

19. Davis, F. 1993, User acceptance of information technology: system characteristics, user perceptions and behavioural impacts, International Journal of Man-Machine Studies, vol. 38, no. 3, pp. 475-87.

20. Dholakia, R. 1999, Going shopping: key determinants of shopping behaviours and motivations in International Journal of Retail and Distribution Management, vol. 27 no. 4, pp. 154-165.

21. Dholakia, R. Uuisitalo, O, 2000, Switching to electronic stores: consumer characteristics and the perception of shopping benefits, International Journal of Retail and Distribution Management, vol.30, no 10, pp 459469.

22. Earl, M., Khan, B, 2001. E commerce is changing the face of IT. MIT Sloan Management Review, vol. fall), pp. 64-72.

23. Engel, J, Kollat, D and Blackwell, R, 1978, Consumer Behaviour, Dryden Press, New York, USA.

24. Engel, J., Blackwell, R. and Minniard, P., 1986. Consumer Behaviour (5th edition), Dryden Press, New York, USA. 
25. Epps, A, 2004, On-line shopping influences and typologies - an expatriate consumer behavioural perspective", Proceedings of the eleventh conference for the American Society of Business and Behavioural Sciences, Las Vegas, Nevada, United States of America February 19-23, 2004, pp 489-581, from conference proceedings CD and online at http://www.asbbs.org/meeting.html

26. Epps. A, 2006, "A classification of web-based shoppers" Proceedings of the second international conference on business, management and economics, from conference proceedings, ICBME, Advances in business and management theory and practice, Cezme, Ismir, Turkey 15-18 June 2006, vol. 3 pp 91-94, also CD and online at http://proceedings.yasar.edu.tr/english/index.html

27. Epps, A, Govers, R and Go, F, 2007, Spirits of web-based shopping past, present and future, New destinations for on-line purchasing, from conference proceedings, Fifth International Business Research Conference, Dubai, United Arab Emirates, 26-27 April, 2007, online at http://www.worldbizconference.com/

28. Evans, M. et al. 2001. Consumer interaction in the virtual era: some qualitative insights, Qualitative Market Research: an International Journal, vol.4, no 3, pp 150-159.

29. Francis, J., White, L., 2002, PIRQUAL: a scale for measuring customer expectations and perceptions of quality in Internet retailing, Evans, K.R., Scheer, L.K., Proceedings of the 2002 American Marketing Association Winter Educators' Conference: Marketing Theory and Applications, Vol. 13, American Marketing Association, Chicago, IL, 263-70.

30. GE (2005) online, available, http://www.yourethebusiness.com/content/tour/con10.asp

31. Goldsmith, R, Flynn, L, 2005 Bricks, clicks, and pix: apparel buyers' use of stores, internet, and catalogs compared, International Journal of Retail and Distribution Management, vol. 33, no. 42005 pp. 271-283.

32. Gould, S. and Lerman, D. 1998. Post-modern versus long-standing cultural narratives in consumer behaviour: an empirical study of Net Girl online, European Journal of Marketing, vol. 32, no 7/8, pp 644654.

33. Gurãu, C, Ranchhod, A and Hackney, R, 2001 Internet transactions and physical logistics: conflict or complementarity? Logistics Information Management, vol. 14, no. 1/2, pp. 33-43.

34. Gurãu, C, Ranchhod, A, 2002, How to calculate the value of a customer-Measuring customer satisfaction: A platform for calculating, predicting and increasing customer profitability, Journal of Targeting, Measurement and Analysis for Marketing. vol. 10, Iss. 3; pg. 203-220.

35. Hamilton, A., 2000, What are your e-shopping habits? ZDNet News, [Online] Available http://techupdate.zdnet.com.

36. Hamilton, R. and Hewer, P., 2000. Electronic commerce and the marketing of Internet banking in the UK, Journal of Financial services Banking vol. 5, no. 2, pp. 135-149.

37. Harvin, R. 2000. In Internet branding, the off-lines have it. Brand week. Jan vol. 24.41 no. 4, pp. 30-31.

38. Hoffman, D. and Novak, T. 1996. Marketing in hypermedia CMEs: conceptual foundations, Journal of Marketing, vol. 60, July, pp 50-68.

39. Hofstede, G., 1980, Cultures Consequences, Sage, Beverly Hills, CA. USA.

40. Kaufman-Scarborough, C. Lindquist, J. 2002 E-shopping in a multiple channel environment, Journal of Consumer Marketing, vol. 19, no. 4, pp.333-350.

41. Kim J, Park, J, 2005A consumer shopping channel extension model: attitude shift toward the online store Journal of Fashion Marketing and Management, vol. 9, no. 1, pp. 106-121

42. Kimber, C. 2002. E-Types - the first classification of consumer behaviour on the Internet, [online] www.webcustomers.co.uk [2002 October 14]

43. Kimelfeld, Y. and Watt, J., 2001.The pragmatic value of on-line transactional advertising: a predictor of purchase intention, Journal of Marketing Communications, vol.7, pp. 137-157.

44. Kolsaker, A. Payne, C. 2000. Engendering trust in e-commerce: a study of gender-based concerns. Marketing Intelligence and Planning vol. 20, no. 4, pp 206-214.

45. Korgaonkar, P. et al, 2001, Web advertising and Hispanics' Journal of Consumer Marketing, vol. 18, no. 2 pp 134- 152.

46. Kotler, P, Armstrong, G, 2004 Principles of Marketing, (10ed), Pearson Prentice Hall, New Jersey, USA.

47. Kotler, P., Armstrong, G., Saunders, J. and Wong, V. 1999, Principles of Marketing. Prentice Hall, Europe. $2^{\text {nd }}$ edition.

48. Kristula, D., 2001 The history of the Internet Online http://www.davesite.com/webstation/net-history.shtml 
49. Lawrence, E. 2000, Business on the internet. Singapore. Wiley.

50. Lee, E, Overby, J, 2004, Creating value for online shoppers: implications for satisfaction and loyalty Journal of Consumer Satisfaction, Dissatisfaction and Complaining Behaviour, vol. 17, pg. 54-68.

51. Liebermann, Y. Stashevshy, S, 2002, Perceived risks as barriers to Internet and e-commerce usage, Qualitative Market Research: An International Journal, vol. 5, no. 4, pp 291-300.

52. Maklan, S, Knox, S, Watson, K., 2001. How is consumer behaviour affected by online relationships? Cranfield University School of Management. CIM E Branding Forum

53. Menon, S. and Kahn, B. 2002, Cross-category effects of induced arousal and pleasure on the Internet shopping experience, Journal of Retailing, vol. 78 no. 1 pp. 31-41.

54. Moon, J. Kim, Y. 2001, Extending the TAM for a World-Wide-Web context, Information and Management, vol. 38, no. 4, pp. 217-30.

55. O'Connor, J., Galvin, E., 2001. Marketing in the digital age $1^{\text {st }}$ ed. Cornwall U.K: Financial Times Professional Education.

56. Park, C and Kim, Y, 2003, Identifying key factors affecting consumer purchase behaviour in an online shopping context International Journal of Retail and Distribution Management, vol. 31, no. 1, pp. 16-29.

57. Peterson, R, Sridhar, R Balasubramanian, S, Bronnenberg, B, 1997, Exploring the implication of the Internet for consumer marketing Journal of the Academy of Marketing Science, vol 25, No.4, pp.329-346.

58. Pollay, R. Mittal, B. 1993. Here's the beef: factors, determinants, and segments in consumer criticism of advertising, Journal of Marketing, Vol. 57, pp. 99-114

59. Porter, M. 1985, Competitive Advantage, Free Press, New York.

60. Porter, M., 2001. Strategy and the Internet, Harvard Business Review, 2001 (March), pp. 63-78.

61. Prabhaker, P. 2000. Who owns the online consumer? Journal of Consumer Marketing, vol. 17, no. 2, pp 158-171

62. Quelch, J. and Klein, L. 1996. The Internet and international marketing, Sloan Management Review, vol. 37, no 3.

63. Rangaswarmy, A., Wind, Y., 1994, Don't walk, just log in electronic markets and what they mean for marketing, Working paper. December.

64. Ranchhod, A and Gurãu, C, 2004 Qualitative issues in IT and organizational processes in implementing marketing strategies Qualitative Market Research: An International Journal, vol. 7, no. 4, pp. 250-256

65. Ranchhod, A, 2004 The changing nature of cyber-marketing strategies, Business Process Management Journal, vol 10, no. 3, pp. 262-276.

66. Ranchhod, A, Zhou, F, and Tinson, J, 2001 Factors influencing marketing effectiveness on the web, Information Resources Management Journal, Jan-Mar 2001, Iss 1, pp 4-13.

67. Richards, T and L Richards, 1991, The NUD.IST qualitative data analysis system.

68. Ryan, G, Valverde, M, 2005, Waiting for service on the internet, defining the phenomenon and identifying the situations Internet Research, vol. 15, no. 2, pp. 220-240.

69. Salisbury, W, Pearson, R and Miller, A, 2001, Perceived security and world wide web purchase intention in Industrial Management and Data Systems, vol. 101, no. 4, pp. 165-177.

70. Sexton, R. Johnson, R. Hignite, M. 2002, Predicting Internet/e-commerce use, Internet research, Electronic Networking Applications and Policy, vol. 12, no. 5, pp. 1066-2243.

71. Sheth, J. Howard, J. 1969. The theory of buyer behaviour, Chichester, Sussex, Dryden Press.

72. Shih, C. 1998. Conceptualising consumer experiences in cyberspace European Journal of Marketing, vol. 32, no. 7/8, pp. 655-663.

73. So, May. Sculli, D. 2002 The role of trust, quality, value and risk in conducting e-business, Industrial management and Data Systems, vol. 102, no. 9, pp. 503-512.

74. Teo, T., Lim, V., Lai, R, 1998, Intrinsic and extrinsic motivation in Internet usage, Omega, International Journal of Management Science, vol. 27, pp. 25-37.

75. Tse, A, 1998, Completing the response rate, emails vs. snail mails, Journal of Market Research Society, vol. 40. no 4

76. Trocchia, P, Janda, S. 2000. A phenomenological investigation of Internet usage among older individuals. Journal of consumer marketing, vol. 17, no. 7, pp 605-616.

77. Ventakesh, A. 1998. Cybermarketscapes and consumer freedoms and identities European Journal of Marketing, vol. 32 no 7/8, pp 664-676. 
78. Wang, C, 1999, Issues and advances in international consumer research: a review and assessment, Journal of International Marketing and Marketing Research, vol. 24, no. 1, pp. 3-21.

79. Yang, $\mathrm{Z}$ and Jun, M. 2002, Consumer perception of e-service quality: From internet purchaser and nonpurchaser perspectives in Journal of Business Strategies; Huntsville; Spring.

\section{NOTES}

